\title{
KRAS or BRAF mutation status is a useful predictor of sensitivity to MEK inhibition in ovarian cancer
}

\author{
N Nakayama', K Nakayama*,', S Yeasmin', M Ishibashi', A Katagiri', K lida', M Fukumoto ${ }^{2}$ and K Miyazaki' \\ 'Departments of Obstetrics and Gynecology, Shimane University School of Medicine, Izumo, Japan; ' ${ }^{2}$ Departments of Pathology, Institute of Development, \\ Aging and Cancer, Tohoku University, Sendai, Japan
}

This study examined the status of KRAS and BRAF mutations, in relation to extracellular signal-regulated protein kinase (ERK) activation in 58 ovarian carcinomas to clarify the clinicopathological and prognostic significance of KRAS/BRAF mutations. Somatic mutations of either KRAS or BRAF were identified in 12 (20.6\%) out of 58 ovarian carcinomas. The frequency of KRAS/BRAF mutations in conventional serous high-grade carcinomas (4.0\%: I/25) was significantly lower than that in the other histological type (32.3\%: I0/3I). Phosphorylated ERKI/2 (p-ERKI/2) expression was identified in 18 (38.2\%) out of 45 ovarian carcinomas. KRAS/BRAF mutation was significantly correlated with International Federation of Gynecology and Obstetrics (FIGO) stage I, II (P<0.00I), and $\mathrm{p}$-ERKI/2 $(\mathrm{P}<0.00 \mathrm{I})$. No significant correlations between KRAS/BRAF mutations or $\mathrm{p}$-ERKI/2 expression and overall survival were found in patients with ovarian carcinoma treated with platinum and taxane chemotherapy $(P=0.2460, P=0.9339$, respectively). Next, to clarify the roles of ERKI/2 activation in ovarian cancers harbouring KRAS or BRAF mutations, we inactivated ERKI/2 in ovarian cancer cells using $\mathrm{Cl}$ - 1040. Cl- 1040 is a compound that selectively inhibits MAP kinase kinase (MEK), an upstream regulator of ERKI/2, and thus prevents ERKI/2 activation. Profound growth inhibition and apoptosis were observed in Cl-I040-treated cancer cells with mutations in either KRAS or BRAF in comparison with the ovarian cancer cells containing wild-type sequences. This was evident in both in vitro and in vivo studies. The findings in this study indicate that an activated ERKI/2 pathway is critical to tumour growth and survival of ovarian cancers with KRAS or BRAF mutations. Furthermore, they suggest that the Cl-I040-induced phenotypes depend on the mutational status of KRAS and BRAF in ovarian cancers. Therefore, ovarian cancer patients with KRAS or BRAF mutations may benefit from $\mathrm{Cl}-1040$ treatment.

British Journal of Cancer (2008) 99, 2020-2028. doi:I0.1038/sj.bjc.6604783 www.bjcancer.com

Published online 18 November 2008

(c) 2008 Cancer Research UK

Keywords: ovarian carcinoma; KRAS; BRAF; mutation; ERKI/2; Cl- 1040

Ovarian carcinoma is the most lethal malignant disease in American women (Wingo et al, 1995) and the most lethal gynaecological cancer in Japan. Its frequency has increased dramatically in the last decade. In more than $70 \%$ of patients with ovarian carcinoma, there is evidence of tumour dissemination beyond the ovaries at diagnosis. In these cases, combined treatment with surgery and chemotherapy is necessary. First-line chemotherapy with platinum drugs and taxanes yields a response rate of over $80 \%$, but almost all patients relapse. Although there are well-established surgical and chemotherapeutic treatments for ovarian cancer, there is a significant opportunity to develop drugs targeting specific molecular pathways. Drugs of this type would be particularly useful for recurrent disease that has acquired chemoresistance. Thus, there is a need for an improved understanding of the molecular pathways of ovarian carcinogenesis. Several genetic alterations are associated with ovarian carcinogenesis. The most frequent genetic abnormalities in ovarian carcinoma are mutations in KRAS, BRAF, and p53 (Singer et al, 2003; Nakayama et al, 2006).

* Correspondence: Dr K Nakayama,Shimane University School of Medicine, Enyacho 89-I, Izumo, Shimane, Japan 693850I;

E-mail: kn88@med.shimane-u.ac.jp

Revised 10 October 2008; accepted 21 October 2008; published online 18 November 2008
Mutations of either BRAF or KRAS lead to constitutive activation (phosphorylation) of their downstream target, mitogen-activated protein kinase (MAPK), also known as extracellular signal-regulated protein kinase (ERK) (Olson and Hallahan, 2004; Wan et al, 2004). Mutations in BRAF or KRAS are correlated with overexpression of activated ERK1/2 in ovarian serous tumours (Hsu et al, 2004). Activation of ERK1/2 in turn activates downstream cellular targets (Peyssonnaux and Eychene, 2001; Allen et al, 2003) including a variety of cellular and nuclear proteins. Although the functions of the RAS-RAF-MEK-ERK pathway and its downstream effectors have been recently explored, only the serous type of ovarian cancer has been studied (Hsu et al, 2004; Pohl et al, 2005). In addition, the biological role of this pathway in the development of ovarian cancers of other histological types is unknown.

Activating KRAS and BRAF mutations typically show mutant exclusivity in tumours (Brose et al, 2002; Davies et al, 2002; Gorden et al, 2003; Singer et al, 2003).

A large proportion of microsatellite-stable colorectal tumour metastases has been shown to accumulate BRAF/KRAS mutations (Oliveira et al, 2007). This suggests an epistatic relationship in which either mutation is sufficient to deregulate a common effector pathway, such as the MAP kinase kinase (MEK)-ERK kinase cascade. If this is the case, tumours arising as a result of a mutation in either KRAS or BRAF should harbour similar 
downstream dependencies. These might represent useful therapeutic targets in ovarian cancer. To test this hypothesis, we examined the consequences of MEK-ERK pathway inhibition using a highly potent and selective inhibitor of MEK1/2, CI-1040 (formerly known as PD184352) (Schaeffer and Weber, 1999; Sebolt-Leopold et al, 1999, 2003; Sebolt-Leopold, 2004). The inhibitor was tested in a collection of ovarian cancer cell lines that showed differing mechanisms of MAP kinase pathway deregulation.

\section{MATERIALS AND METHODS}

\section{Tissue samples}

Formalin-fixed, paraffin-embedded tissue samples of 58 ovarian cancers, including 27 serous carcinomas, 20 mucinous carcinomas, and 11 endometrioid carcinomas were used in this study. These samples were obtained from the Department of Obstetrics and Gynecology at the Shimane University Hospital. Diagnosis was based on conventional morphological examination of sections stained with haematoxylin and eosin (H\&E) staining, and tumours were classified according to the WHO (World Health Organization) classification. Tumour staging was carried out according to the International Federation of Gynecology and Obstetrics (FIGO) classification. The clinicopathological characteristics of the patients included in this study are summarised in Table 1. All the patients were primarily treated with cytoreductive surgery and adjuvant platinum and taxane chemotherapy (CBDCA AUC5, Paclitaxel $175 \mathrm{mg} \mathrm{m}^{-2}$ or Docetaxel $70 \mathrm{mg} \mathrm{m}^{-2}$ ). All the cases received 6-12 courses of this regimen. The acquisition of tumour tissues was approved by the Shimane University Institutional Review Board. The paraffin tissue blocks were organised into tissue microarrays, which were made by removing $3 \mathrm{~mm}$ diameter cores of tumour from each block. The areas for coring were selected by surgical pathologists (MF) on the basis of a review of the H\&E slides.

\section{Cell culture and cell lines}

OVCAR3, SKOV3, A2780, MDAH2774 (serous carcinoma), and ES2 (clear cell carcinoma) human ovarian cancer cell lines were obtained from the American Tissue Culture Center (Rockville, MD, USA). The human ovarian carcinoma cell line KF28 (serous carcinoma) was a kind gift from Dr Yoshihiro Kikuchi (Ohki Memorial Kikuchi Cancer Clinic for Women, Saitama, Japan) (Yamamoto et al, 2000). The MPSC1 cell line was established from a low-grade serous carcinoma and was a kind gift from Dr le-Ming Shih (Johns Hopkins Medical Institutions, Baltimore, MD, USA). OVK\#18 (serous carcinoma) human ovarian cancer cell line was obtained from Tohoku University (Sendai, Japan). OMC3 (mucinous carcinoma) and JHOC5 (clear cell carcinoma) human ovarian cancer cell lines were also obtained from Riken Bioresource Center (Ibaragi, Japan). In addition, human papillomavirus E6/E7immortalised primary cultures of normal ovarian surface epithelium (OSE) were also included in this study. IOSE27, a normal OSE cell line, was obtained from the American Tissue Culture Center. OSE7 and OSE10 normal OSE cell lines were a kind gift from Dr Hidetaka Katabuchi (Kumamoto University, Kumamoto, Japan).

A set of primary cultures was established from ovarian cancers, including POC-1, POC-2, and POC-3. The acquisition of anonymous tissue specimens was approved by the Shimane University Institutional Review Board.

The diagnoses were confirmed by a surgical pathologist before the tumour samples were harvested for experiments. Primary tumour cultures were established from freshly isolated tumour samples by immunosorting or trypsinisation. For immunosorting, fresh tumour tissues were minced and incubated with collagenase
Table I Mutational status of KRAS and BRAF genes and p-ERKI/2 expression in ovarian cancer

\begin{tabular}{|c|c|c|c|c|c|}
\hline Case no. & Histology & Grade & KRAS & BRAF & p-ERKI/2 \\
\hline 1 & Serous & I & WT & WT & $N$ \\
\hline 2 & Serous & I & WT & $\begin{array}{l}\text { TI796A } \\
\text { V600E }\end{array}$ & $P$ \\
\hline 3 & Serous & 2 & WT & WT & $N$ \\
\hline 4 & Serous & 3 & WT & WT & $N$ \\
\hline 5 & Serous & 3 & WT & WT & $N$ \\
\hline 6 & Serous & 2 & WT & WT & $P$ \\
\hline 7 & Serous & 2 & WT & WT & $N$ \\
\hline 8 & Serous & 2 & WT & WT & $P$ \\
\hline 9 & Serous & 3 & WT & WT & $N$ \\
\hline 10 & Serous & 3 & WT & WT & $P$ \\
\hline | | & Serous & 3 & WT & WT & $P$ \\
\hline 12 & Serous & 3 & WT & WT & $N$ \\
\hline 13 & Serous & 3 & WT & WT & $N$ \\
\hline 14 & Serous & 3 & $\begin{array}{l}\text { G35T/ } \\
\text { G12V }\end{array}$ & WT & $P$ \\
\hline 15 & Serous & 3 & WT & WT & $N$ \\
\hline 16 & Serous & 3 & WT & WT & $N$ \\
\hline 17 & Serous & 3 & WT & WT & $N$ \\
\hline 18 & Serous & 3 & WT & WT & $P$ \\
\hline 19 & Serous & 3 & WT & WT & $N$ \\
\hline 20 & Serous & 3 & WT & WT & $N$ \\
\hline 21 & Serous & 3 & WT & WT & $N$ \\
\hline 22 & Serous & 3 & WT & WT & $P$ \\
\hline 23 & Serous & 3 & WT & WT & $P$ \\
\hline 24 & Serous & 3 & WT & WT & $N$ \\
\hline 25 & Serous & 3 & WT & WT & $N$ \\
\hline 26 & Serous & 3 & WT & WT & $P$ \\
\hline 27 & Serous & 3 & WT & WT & $P$ \\
\hline 28 & Mucinous & I & WT & $\begin{array}{l}\text { TI796A } \\
\text { V600E }\end{array}$ & $\mathrm{P}$ \\
\hline 29 & Mucinous & I & $\begin{array}{l}\text { G35A/ } \\
\text { G12D }\end{array}$ & $\begin{array}{l}\text { TI796A } \\
\text { V600E }\end{array}$ & $P$ \\
\hline 30 & Mucinous & I & WT & WT & $N$ \\
\hline 31 & Mucinous & I & WT & $\begin{array}{l}\text { TI796A } \\
\text { V600E }\end{array}$ & $P$ \\
\hline 32 & Mucinous & I & $\begin{array}{l}\text { G35T/ } \\
\text { GI2V }\end{array}$ & WT & $P$ \\
\hline 33 & Mucinous & 2 & WT & WT & $\mathrm{N}$ \\
\hline 34 & Mucinous & 2 & WT & WT & $N$ \\
\hline 35 & Mucinous & 2 & $\begin{array}{l}\text { G35A/ } \\
\text { GI2D }\end{array}$ & WT & $\mathrm{P}$ \\
\hline 36 & Mucinous & 2 & WT & WT & $N$ \\
\hline 37 & Mucinous & 2 & WT & WT & $N$ \\
\hline 38 & Mucinous & 2 & WT & WT & $N$ \\
\hline 39 & Mucinous & 2 & WT & WT & $N$ \\
\hline 40 & Mucinous & 2 & WT & WT & $P$ \\
\hline 41 & Mucinous & 3 & WT & WT & $P$ \\
\hline 42 & Mucinous & 3 & WT & WT & $\mathrm{N}$ \\
\hline 43 & Mucinous & 3 & WT & WT & $N$ \\
\hline 44 & Mucinous & 3 & WT & WT & $N$ \\
\hline 45 & Mucinous & 3 & WT & WT & $N$ \\
\hline 46 & Mucinous & 3 & WT & WT & $P$ \\
\hline 47 & Mucinous & 3 & WT & WT & $N$ \\
\hline 48 & Endometrioid & I & WT & $\begin{array}{l}\text { TI796A } \\
\text { V600E }\end{array}$ & $P$ \\
\hline 49 & Endometrioid & I & WT & WT & $N$ \\
\hline 50 & Endometrioid & 2 & WT & WT & $P$ \\
\hline 51 & Endometrioid & 2 & WT & WT & $N$ \\
\hline 52 & Endometrioid & 2 & $\begin{array}{l}\text { G35A/ } \\
\text { G12D }\end{array}$ & WT & $P$ \\
\hline 53 & Endometrioid & 2 & $\begin{array}{l}\text { G35A/ } \\
\text { G12D }\end{array}$ & WT & P \\
\hline 54 & Endometrioid & 2 & G35T/GI2V & WT & $P$ \\
\hline 55 & Endometrioid & 3 & G35A/GI2D & WT & $P$ \\
\hline 56 & Endometrioid & 3 & WT & WT & $N$ \\
\hline 57 & Endometrioid & 3 & WT & WT & $P$ \\
\hline 58 & Endometrioid & 3 & WT & WT & $N$ \\
\hline
\end{tabular}

$\mathrm{N}=$ negative; $\mathrm{P}=$ positive; $\mathrm{WT}=$ wild type. 
A $\left(2 \mathrm{mg} \mathrm{ml}^{-1}\right)$ at $37^{\circ} \mathrm{C}$ for $40 \mathrm{~min}$. After filtration through sieve membranes (with $100 \mu \mathrm{m}$ pores), tumour cells were immunosorted using an epithelial specific antigen (Ep-CAM) antibody bound to Dynal $^{\mathrm{TM}}$ beads (Dynal, Oslo, Norway) following the vendor's instructions (Nakayama et al, 2006). Freshly isolated tumour cells were allowed to grow in culture and were used for experiments within two passages.

\section{Mutational analysis of $K R A S$ and $B R A F$}

Genomic DNA was purified from all the cell lines and formalinfixed, paraffin-embedded tissues using a Qiaquick polymerase chain reaction (PCR) purification kit (Qiagen, Valencia, CA, USA). PCR was then carried out followed by nucleotide sequencing using the iCycler (Bio-Rad, Hercules, CA, USA). Exon 1 of KRAS and exon 15 of $B R A F$ were both sequenced, as these mutational hot spots together harbour nearly all published mutations (Davies et al, 2002; Singer et al, 2002, 2003; Sieben et al, 2004). The primers for PCR and sequencing were manufactured by GeneLink (Hawthorne, NY, USA), and their sequences were described in an earlier report (Nakayama et al, 2006). The sequences were analysed using the Lasergene programme, DNASTAR (Madison, WI, USA).

\section{Immunohistochemistry}

Expression of the active phosphorylated ERK1/2 (p-ERK1/2) was assessed by immunohistochemistry and western blot analysis. The antibody used in this study was a rabbit polyclonal antibody that reacted with phosphorylated but not unphosphorylated ERK1/2 (Cell Signaling Technology). Immunohistochemistry was carried out on tissue microarrays at a dilution of 1:1000 followed by detection with the En Vision + System using the peroxidase method (DAKO, Carpinteria, CA, USA). The percentage of positive cells was estimated by randomly counting $\sim 500$ tumour cells from three different high-power fields $(\times 40)$ within one specimen. A positive reaction was defined as a discrete localisation of the brown chromagen in the nucleus or cytoplasm. Cases in which more than $5 \%$ of the tumour cells showed detectable immunoreactivity were scored as positive.

\section{Western blot analysis}

Cell lysates were prepared by dissolving cell pellets in Laemmli sample buffer (BioRad, Hercules, CA, USA) supplemented with $5 \%$ $\beta$-mercaptoethanol (Sigma, St Louis, MO, USA). Western blot analysis was performed on ovarian cancer/OSE cell lines/cultures, including OVCAR3, SKOV3, A2780, MDAH2774, ES2, MPSC1, KF28, OVK\#18, OMC3, JHOC5, PC1, PC2, PC3, IOSE29, OSE7, and OSE10. Similar amounts of total protein from each lysate were loaded and separated on $10 \%$ Tris-Glycine-SDS polyacrylamide gels (Novex, San Diego, CA, USA) and electroblotted to Millipore Immobilon-P polyvinylidene difluoride membranes. The membranes were probed with an active ERK1/2 antibody (pTEpY, $1: 5000)$ (Cell Signaling Technology) followed by a peroxidaseconjugated anti-mouse or anti-rabbit immunoglobulin $(1: 20000)$. The same membrane was probed with an antibody that reacted with total ERK1/2 (1:5000) (Cell Signaling Technology) for loading controls. Western blots were developed by chemiluminescence (Pierce, Rockford, IL, USA).

\section{Cell-growth assays}

For the cell-growth assay, cells were plated at the same density $\left(3 \times 10^{3}\right.$ cells per well $)$ in 96 -well plates. An methyl thiazoyl tetrazorium (MTT) cell-growth assay was performed (Nakayama et al, 2001) $96 \mathrm{~h}$ after treating the cells with CI-1040 (provided by Pfizer, Inc., New York, NY, USA) at $5 \mu \mathrm{M}$ or with dimethyl sulphoxide (DMSO) (control). The data were expressed as a percentage of the DMSO control. The mean and standard deviation (s.d.) were obtained from three experiments. Apoptotic cells were detected with 4',6-diamidino-2-phenylindole (DAPI) staining. The data were expressed as the mean \pm 1 s.d. from triplicates. To confirm the presence of apoptotic cells, DAPI-stained cells were also stained with Annexin V dye. Bromodeoxyuridine (BrdUrd) uptake and staining were measured using a cell proliferation kit (Amersham, Buckinghamshire, England, UK) and apoptotic cells were detected using an Annexin $\mathrm{V}$ staining kit (Bio Vision, Mountain View, CA, USA). The percentages of BrdUrd-positive and Annexin V-positive cells were determined by counting approximately 400 cells from each well in 96 -well plates. The data were expressed as the mean \pm 1 s.d. of triplicates.

\section{Tumour xenograft in nude mice}

To confirm the findings of a CI-1040 effect in vitro, we injected $3 \times 10^{6}$ MDAH2774 or SKOV3 cells into the intraperitoneal tissue of $n u / n u$ mice (4 weeks of age). Four weeks BALB/c $n u / n u$ mice were purchased from Charles River Japan Inc. (Kanagawa, Japan). CI-1040 was prepared in a vehicle of $10 \%$ Cremophore EL (Sigma, St Louis, MO, USA), $10 \%$ ethanol, and $80 \%$ water. When the model for the mouse study was first designed, the end point was set to be the day when the mice began to produce ascites, or acute gain of weight due to tumour growth, for reasons of ethical origin. Tumours that start causing ascites have a chance of developing other malignant characteristics, which can become harmful progressively. Four mice were used for each experimental group. During the study, the mice were killed when it was discovered that the abdomen of one of the mice had begun to distend because of ascites. One week after tumour-cell injection, either CI-1040 (CI$1040,150 \mathrm{mg} \mathrm{kg}^{-1}$, resuspended in $10 \%$ Cremophore EL (Sigma), $10 \%$ ethanol, and $80 \%$ water) or a vehicle only (10\% Cremophore EL (Sigma), $10 \%$ ethanol, and $80 \%$ water) were injected intraperitoneally (i.p.) once daily for 3 weeks. The total dose of CI-1040 for each mouse was $63 \mathrm{mg}$. Four weeks after the cell injection (three weeks after CI-1040 injection), the abdomens of the control group mice had begun to distend. The time for termination of the experiment was dictated by the aforementioned ethical reasons (tumour ascites in controls), and this endpoint was observed at that time. We anaesthetised the mice before they were rendered moribund by the experiment. The total tumour weight at that time was around $500 \mathrm{mg}$. Necropsy was carried out on all mice to assess i.p. tumour growth, and the tumours were excised and weighed. Animal experiments were carried out in accordance with the regulations of the Institutional Ethical Commission (Shimane University) and of the United Kingdom Co-ordinating Committee on Cancer Research guidelines (Workman, 1998).

\section{Statistical methods for clinical correlation}

Overall survival was calculated from the date of diagnosis to the date of death or last follow-up. Patients with either KRAS or BRAF mutations had similar performance status distributions. The data were plotted as Kaplan-Meier curves, and the statistical significance was determined by the log-rank test. Data were censored when patients were lost to follow-up. The Student's $t$-test was used to examine the statistical significance in the difference of growthassay data.

\section{RESULTS}

\section{Identification of $K R A S$ and $B R A F$ mutations}

The mutational status of KRAS and $B R A F$ in all 45 ovarian carcinomas is summarised in Table 1 . Somatic mutations of KRAS were identified in $8(13.7 \%)$ out of 58 ovarian carcinomas. In 
contrast, somatic mutations of $B R A F$ were identified in $5(8.6 \%)$ out of 58 ovarian carcinomas. Somatic mutations of either KRAS or $B R A F$ were identified in $12(20.6 \%)$ out of 58 ovarian carcinomas. Most KRAS mutations were located at codon 12 and all BRAF mutations at codon 600. Both of these codons are mutation hot spots. Interestingly, simultaneous mutations of KRAS and BRAF did not occur in the tested ovarian carcinomas with the exception of one mucinous case.

A panel of ovarian cancer cell lines and primary cultures was first analysed for tumour mutation status in the KRAS and BRAF genes. As shown in Figure 1, three ovarian cancer cell lines harboured either KRAS or BRAF mutations. The frequency of either KRAS or BRAF mutations in conventional serous high-grade carcinomas $(4.0 \%: 1 / 25)$ was significantly lower than in the other histological type $(32.2 \%: 10 / 31)$.

\section{Relationship between $K R A S / B R A F$ mutations and p-ERK1/2 expression or clinicopathological factors}

The immunoreactivity of active p-ERK1/2 was detected in both the nucleus and the cytoplasm of the tumour cells (Figure 2). This is consistent with an earlier report (Mizumoto et al, 2007). Positive active p-ERK1/2 was identified in $27(46.6 \%)$ out of 58 ovarian carcinomas. The patients were stratified into two groups depending on the mutational status of KRAS/BRAF. The relationships between KRAS/BRAF mutations and clinicopathological factors, including p-ERK1/2 expression are shown in Table 2 . There was no significant correlation between KRAS/BRAF mutations and the patient's age. The results in Table 2 show that KRAS/BRAF mutation is correlated significantly with FIGO stage I, II $(P<0.001)$, and $\mathrm{p}$-ERK $1 / 2(P<0.001)$. In addition, there were significant correlations between KRAS/BRAF mutations and pathological grade $(P=0.004)$, and histological subtype $(P=0.014)$.

\section{Effect of KRAS/BRAF mutations or p-ERK1/2 on the prognosis of ovarian carcinomas}

Next, we examined the prognostic effect of KRAS/BRAF mutations and p-ERK1/2 expression. Out of the 58 samples that we examined, 45 were available for prognostic analysis. Kaplan-Meier estimates of overall survival are plotted in Figure 3. There was no significant relationship between KRAS/BRAF mutations or p-ERK1/2 expression and overall survival in patients with ovarian carcinoma
( $P=0.2460, P=0.9339$, respectively). Univariate analysis showed that only FIGO stage III, IV affected the overall survival of patients with ovarian carcinoma significantly $(P=0.014)$.

\section{Effects of ERK1/2 inactivation on ovarian carcinoma in vitro}

A panel of ovarian cancer cell lines and primary cultures of ovarian cancer were first analysed for KRAS and BRAF gene mutation status. Mutational status was correlated with growth inhibition and apoptosis induction by the MEK inhibitor CI-1040 that prevented activation of the downstream target, ERK1/2. Western blot analysis showed a dose-dependent effect on the expression of active ERK1/ 2 in ES2 cells, and active ERK1/2 was not detectable $6 \mathrm{~h}$ after treating the cells with CI-1040 at a concentration of $5 \mu \mathrm{M}$ (Figure 4). As shown in Figure 5, four of the tumours harbouring either KRAS or $B R A F$ mutations showed a marked reduction $(<50 \%$ of DMSO control) in the cell number in the CI-1040-treated group as compared with the other 14 tumours containing wild-type KRAS and BRAF $(P<0.001)$. CI-1040 had no significant effect on the growth of normal cells, including the OSE cells. It is likely that $K R A S / B R A F$ mutation is not the only determinant for activating ERK1/2. Therefore, we analysed p-ERK1/2 expression in each of the cell lines listed in Figure 5. Only four of these cell lines, MDAH2774, ES2, MPSC1, and POC1, strongly expressed p-ERK1/2. SKOV3 and A2780 showed weak expression of ERK1/2.These results suggest that activation of ERK1/2 may depend on KRAS/ $B R A F$ mutation in ovarian cancer cells.

To assess the mechanisms underlying growth inhibition by CI-1040, we measured the percentages of BrdUrd-labelled cells and Annexin V-labelled cells to estimate proliferation and apoptosis, respectively. We found that CI-1040 significantly reduced cellular proliferation and induced apoptosis in cell lines with either KRAS or $B R A F$ mutations in comparison with cell lines with wild-type sequences (Figure 6, Supplementary Figure 1).

\section{Effects of CI-1040 ERK1/2 inactivation on ovarian carcinomas in vivo}

On the basis of the above findings, we investigated whether CI-1040 had a growth-inhibitory effect on tumour formation and development in vivo. Tumour xenografts from both MDAH2774 (KRAS mutant) and SKOV3 (wild type of KRAS and BRAF) cell

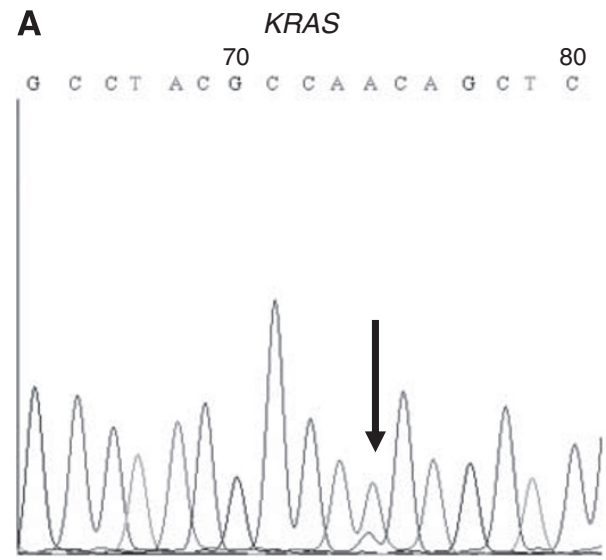

$\mathrm{G}$ to $\mathrm{T}$ mutation at nucleotide 35 (reverse strand)
B
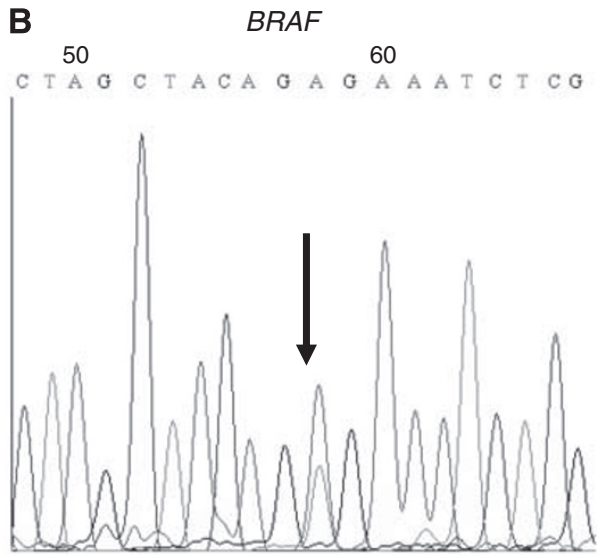

T to A mutation at nucleotide 1796

(forward strand)

Figure I Chromatograms of KRAS and BRAF mutational status in three representative ovarian cancer cells. (A) Left panel (MDAH2774) showing a point mutation in the KRAS gene. (B) Right panel (ES2) showing a point mutation in the BRAF gene. Arrows represent spike which indicates mutation. 

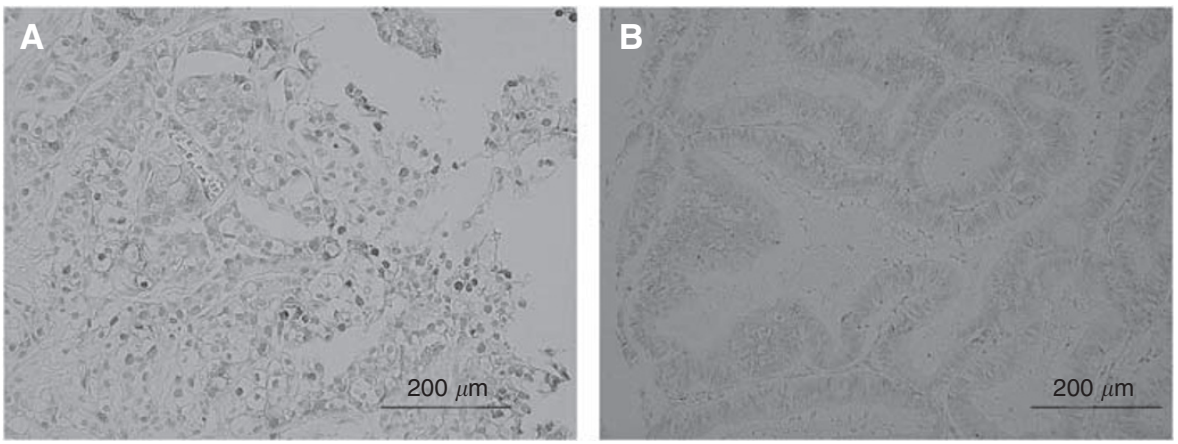

Figure 2 Immunohistochemical staining of phosphorylated extracellular-regulated kinase $(p-E R K \mid / 2)$. (A) Intense immunoreactivity is present in both the nucleus and the cytoplasm in this ovarian carcinoma. (B) A case with negative staining of phosphorylated ERKI/2 (p-ERKI/2).

Table 2 Association between KRAS/BRAF mutational status and clinicopathological factors in patients with ovarian cancer

\begin{tabular}{|c|c|c|c|c|}
\hline \multirow[b]{2}{*}{ Factors } & \multirow[b]{2}{*}{ Patients } & \multicolumn{2}{|c|}{ KRAS/BRAF mutation } & \multirow[b]{2}{*}{$P$-value } \\
\hline & & Negative & Positive & \\
\hline \multicolumn{5}{|l|}{ FIGO stage } \\
\hline I, II & 18 & 8 & 10 & $<0.001$ \\
\hline III, IV & 38 & 38 & 2 & \\
\hline \multicolumn{5}{|l|}{ Grade } \\
\hline GI & 9 & 3 & 6 & $<0.001$ \\
\hline G2, G3 & 49 & 43 & 6 & \\
\hline \multicolumn{5}{|l|}{ Histology } \\
\hline Serous & 28 & 26 & 2 & 0.014 \\
\hline Others & 30 & 20 & 10 & \\
\hline \multicolumn{5}{|l|}{ Age (years) } \\
\hline$<60$ & 35 & 28 & 7 & 0.293 \\
\hline$\geqslant 60$ & 23 & 17 & 6 & \\
\hline \multicolumn{5}{|l|}{$p-E R K I / 2$} \\
\hline Positive & 27 & 15 & 12 & $<0.001$ \\
\hline Negative & 31 & 31 & 0 & \\
\hline
\end{tabular}

FIGO, International Federation of Gynecology and Obstetrics; MAPK, mitogenactivated protein kinase; ERKV2, Extracellular signal-regulated protein kinases I/2.

lines were established in a $n u / n u$ mouse model. All mice injected with CI-1040 developed significantly smaller intra-abdominal xenograft tumours than the mice carrying diluent control cells of the KRAS mutant cell line MADH2774 (Figure 7A). There were no differences in intra-abdominal xenograft tumour weights between the CI-1040-treated group and control groups transplanted with the wild-type KRAS/BRAF cell line SKOV3 (Figure 7B). Histological examination of the tumours after CI-1040 treatment showed inactivation of p-ERK1/2 in tumour cells based on immunohistochemistry (Figure 7C and D).

\section{DISCUSSION}

The significantly higher frequency of KRAS/BRAF mutations in non-serous type carcinomas compared with conventional highgrade serous carcinomas in this study is a finding of great interest. It suggests that conventional high-grade serous and non-serous tumours may be distinguished on the basis of characteristic genetic alterations. In addition, this observation further supports the theory that ovarian carcinoma arises from multiple pathways (Shih Ie and Kurman, 2004, 2005). In this model, conventional high-grade serous and non-serous carcinomas develop independently from one another and are characterised by different molecular genetic changes and gene expression profiles (Schwartz et al, 2002; Marquez et al, 2005).

We reported earlier that KRAS or BRAF mutations were quite common in low-grade serous ovarian carcinomas but rare in conventional high-grade serous carcinomas (Nakayama et al, 2006). Our present results showing low frequencies of either KRAS or $B R A F$ mutations in conventional high-grade serous carcinoma are consistent with our earlier reports (Nakayama et al, 2006).

$\mathrm{V} 600 \mathrm{E}$ is the most common BRAF mutation in ovarian cancer (Singer et al, 2003; Sieben et al, 2004; Shih Ie and Kurman, 2005; Nakayama et al, 2006). However, mutations at E585K and G463E have also been reported in ovarian cancer samples and cell lines (Davies et al, 2002). Therefore, further studies are needed to clarify the effects of other BRAF mutations in ovarian cancer, and to completely describe the mutation profile of $K R A S-B R A F$ signalling in established ovarian cancer cell lines.

In this study, we also showed that the ERK-MAPK pathway was activated in $15(33.3 \%)$ out of 45 ovarian carcinomas and activation depended on the mutational status of KRAS and BRAF. This is in contrast with a recent report showing that this pathway is frequently activated independent of the status of KRAS and $B R A F$ in endometrioid-type endometrial cancer (Mizumoto et al, 2007). This discrepancy may be because of differences in organspecific oncogenic pathways. The RAS-RAF-MEK-ERK pathway may play an important role in ovarian carcinogenesis but not in endometrial carcinogenesis. Similarly, alternative pathways for ERK activation, such as crosstalk with the PI3K pathway, exist in endometrial cancer but are rare in ovarian cancer. Indeed, PI3K signalling by either PIK3CA or PTEN mutations occurs in $40 \%$ of endometrial cancers but in $<5 \%$ of ovarian cancers (Tashiro et al, 1997; Oda et al, 2005; Kolasa et al, 2006; Nakayama et al, 2006).

In this study, KRAS IBRAF mutations tended to have a favourable but not statistically significant effect on overall survival. Our findings contrast with a recent report showing a positive correlation between a KRAS or BRAF mutation and clinical aggressiveness in colorectal, non-small-cell lung, and thyroid cancers (Lievre et al, 2006; Lee et al, 2007; Massarelli et al, 2007). This difference in prognostic significance between ovarian cancer and the latter types is intriguing, and it probably reflects organspecific roles of the KRAS/BRAF pathway. In this study, 8 out of 9 $K R A S / B R A F$ mutations were identified in early stage (stage I, II) tumours. This may reflect a more indolent course of tumours with KRAS/BRAF mutations.

In an earlier report, advanced ovarian cancer patients (stage III, IV) with p-ERK expression had a longer overall survival than patients with low p-ERK values (Hsu et al, 2004). However, we did not find a significant correlation between p-ERK expression and overall survival in our study. This difference may be because of a 

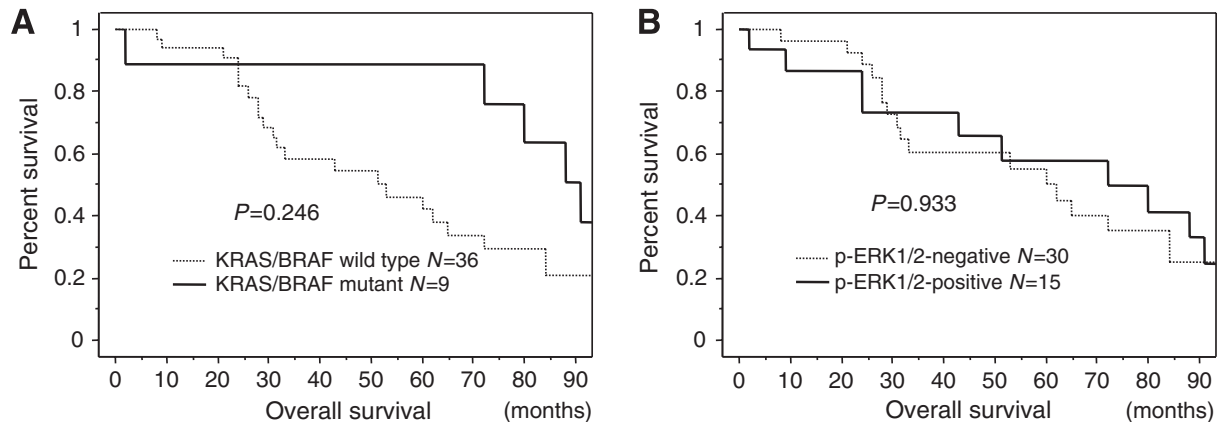

Figure 3 Kaplan-Meier survival curve in 45 patients with ovarian carcinoma according to KRAS/BRAF mutation and phosphorylated ERK ( $\mathrm{p}$-ERK) expression. (A) KRAS/BRAF mutational status correlates with favourable overall survival in patients with ovarian carcinoma. (B) p-ERKI/2 expression does not correlate with shorter overall survival in patients with ovarian carcinoma.

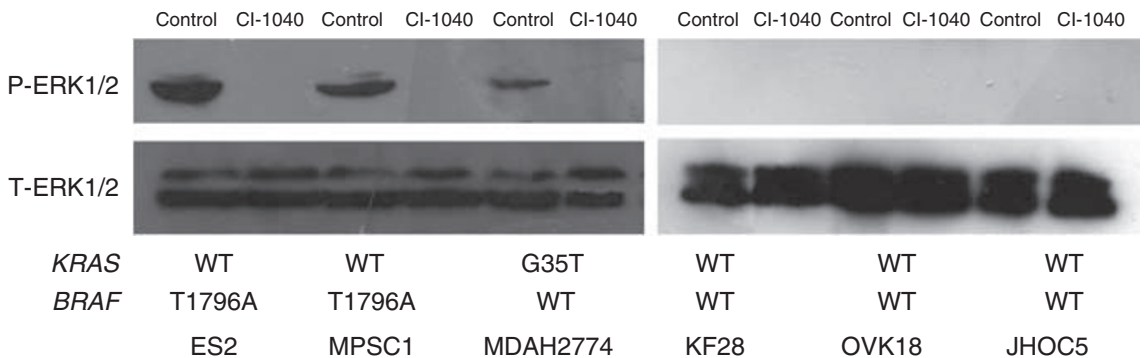

Figure 4 Western blot analysis. Expression of phosphorylated ERKI/2 (p-ERKI/2) is undetectable in all Cl-1040-treated samples. A similar amount of protein was loaded in $\mathrm{Cl}-1040$ and DMSO-treated samples as evidenced by a similar intensity of total ERKI/2. D, DMSO treatment, C, and Cl-I040 treatment.

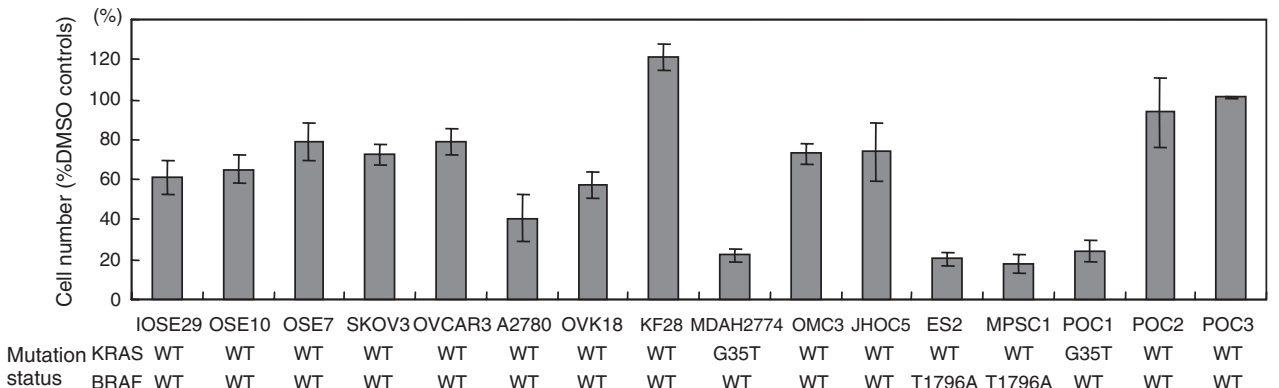

Figure 5 Effects of $\mathrm{Cl}-\mathrm{I} 040$ on cell proliferation. Cells were counted after $72 \mathrm{~h}$ of $\mathrm{Cl}$ - I040 or DMSO (control) treatment. The mutational status of KRAS and $B R A F$ for each sample is shown under the cell lines and primary cancer cell cultures. Ovarian cancers with mutations in either KRAS or BRAF are more sensitive to growth inhibition by $\mathrm{Cl}$ - 1040 than those with wild-type (WT) sequences.

higher percentage of early-stage ovarian cancers and endometrioid and mucinous histology tumours being included in this study as compared with the earlier study.

Although the biological roles of the RAS-RAF-MEK-ERK pathways in human cancer have been thoroughly investigated, there have been no recent studies. Therefore, it is not known whether the activation of KRAS or BRAF mutations alters the effects of these pathways on tumour progression. In this study, we carried out a genotype-phenotype correlation of ovarian cancer cells using a MEK inhibitor, CI-1040. In this study, we focussed on CI-1040 because it inhibited the common downstream target in the RAS signalling pathway. Therefore, CI-1040 has the potential to be developed into a drug for the treatment of ovarian carcinomas in patients with either KRAS or BRAF mutations. An oral formulation of CI-1040 had already been shown to be an effective MEK inhibitor and was generally well tolerated in a multicentre phase II study (Rinehart et al, 2004). Our results provide compelling evidence that the biological effects of the ERK signalling pathway depend on the mutational status of its upstream regulators, (i.e.), the KRAS and BRAF genes.
Ovarian carcinomas with mutations in either KRAS or BRAF were more sensitive to growth inhibition and apoptosis induction by the MEK inhibitor, CI-1040. This observation suggests that ovarian carcinomas with mutations in either KRAS or BRAF are more highly dependent on the activation of the RAS - RAF-MEKERK pathway for cell proliferation and survival than those without such mutations. Thus, inactivation of ERK1/2 results in marked growth inhibition in ovarian carcinomas with mutations in $K R A S$ or $B R A F$ in comparison with only a modest effect on wildtype tumours. The above observations lend strong support to the view of 'kinase addiction' by which the activating mutations in the kinase pathway confer susceptibility of the tumours to an inhibitor (Sebolt-Leopold et al, 1999; Arteaga and Baselga, 2004). In microsatellite-unstable colorectal cancer cell lines, the effect of BRAF inhibition depended on whether the cell harboured a $B R A F$ or a KRAS mutation. BRAF inhibition by small interfering RNA resulted in significantly decreased proliferation and increased apoptosis in the $B R A F$ mutant lines. In contrast, this effect was not seen in the KRAS mutant lines (Preto et al, 2008). Cells carrying $B R A F$ mutations have also been shown to be more sensitive to 
A

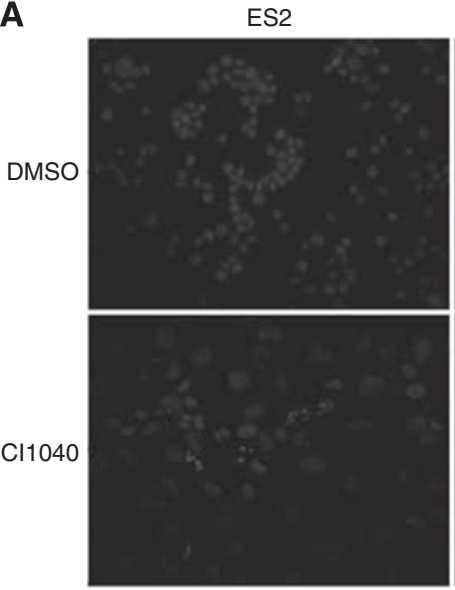

B

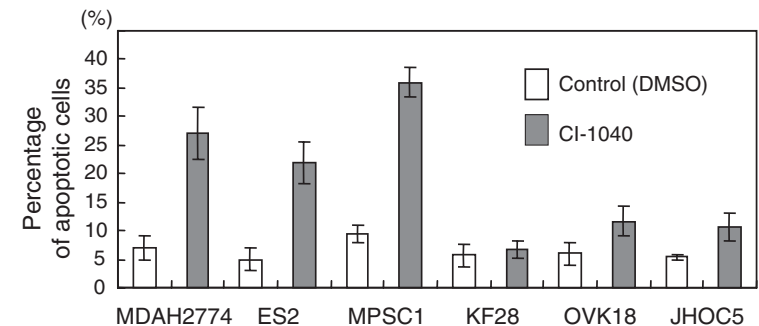

C
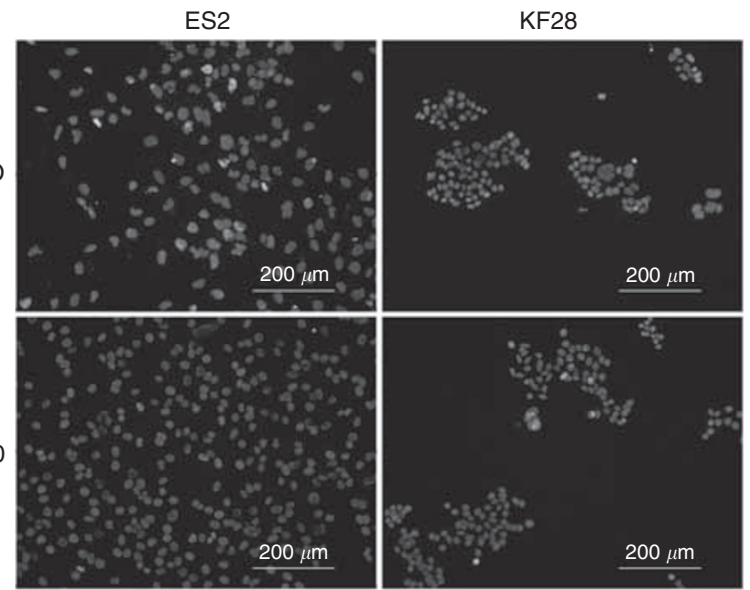

D

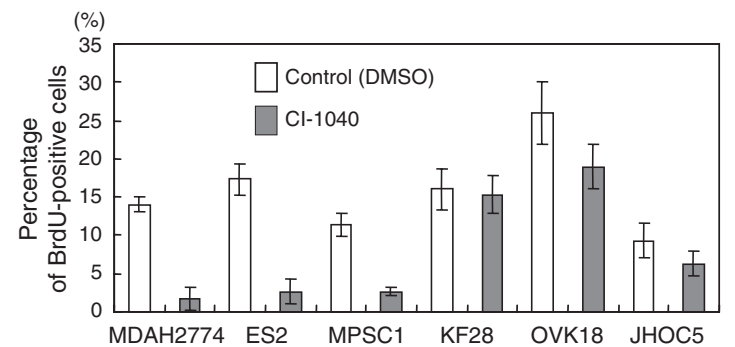

Figure 6 Detection of apoptotic cells and proliferation cells. (A) The Cl- 1040 -treated ES2 cells, but not KF28 cells, show morphological features typical of apoptosis. (B) Apoptotic cells are quantified by counting them under a fluorescent microscope. (C) Treatment with Cl-I040 decreases DNA synthesis as measured by BrdUrd uptake in ES2 cells, but not KF28 cells. (D) Proliferation is estimated by counting BrdUrd-stained cells under a fluorescent microscope. The experiment was performed $72 \mathrm{~h}$ after $\mathrm{Cl}-1040$ or DMSO treatment.
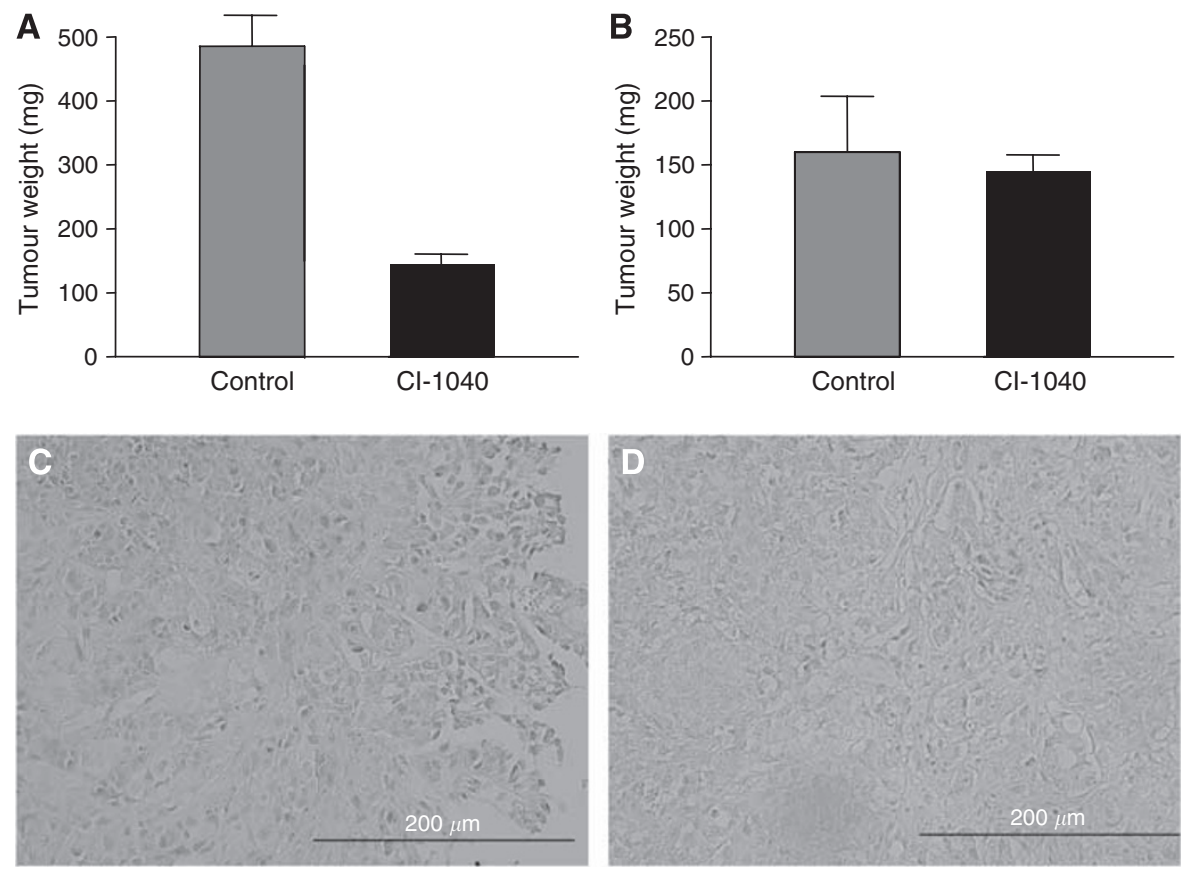

Figure 7 Effects of $\mathrm{Cl}$ - 1040 in a mouse xenograft model. (A) Cl- 1040-treated cells produced small tumour nodules in the peritoneal cavity. However, the diluent control-treated cells grew much larger i.p. tumours in KRAS mutant MDAH2774 cells. (B) In contrast, there were no differences in tumour weights between $\mathrm{Cl}$-1040-treated cells and control-treated cells in wild-type (WT) KRAS/BRAF SKOV3 cells. Tumours were excised and weighed. The data are expressed as the total tumour weight from each mouse. (C and $\mathbf{D})$ Immunohistochemical staining of phosphorylated extracellular-regulated kinase I/2 ( $p$ ERKI/2) in tumours with KRAS mutant MDAH2774 cells. (C) Intense immunoreactivity is present in both the nucleus and the cytoplasm in Cl-I040untreated tumour. (D) Immunoreactivity is absent in both the nucleus and the cytoplasm in $\mathrm{Cl}$ - I040-untreated tumour cells. 
MEK inhibitors than cells with RAS mutations (Solit et al, 2006). This raises the possibility that KRAS and BRAF mutant cancer cells might be differentially dependent on signalling mechanisms that involve MEK. This difference in sensitivity to the RAS-RAFMEK-ERK pathway between ovarian cancer and the latter types is intriguing, and it probably reflects organ-specific roles of the KRAS and BRAF oncogenes.

In light of our in vivo and in vitro findings, we propose that ovarian cancer patients with KRAS or BRAF mutations be considered for MEK inhibitor (CI-1040) therapy if they recur after conventional platinum and taxane chemotherapy.

Thus far, the MEK inhibitor CI-1040 has fared poorly in clinical trials for breast, colon, and lung cancer (Rinehart et al, 2004). However, its favourable therapeutic index and high selectivity may outweigh its shortcomings in KRAS and BRAF mutant ovarian cancer. Therefore, we recommend that in further clinical trials of MEK inhibitors for ovarian cancer, patients are stratified on the basis of KRAS/BRAF mutational status.

In summary, we have shown that the phenotypic change in ovarian carcinomas in response to ERK1/2 inactivation depends on the mutational status of KRAS and BRAF. The findings in this study provide new insight into the biological roles of the RAS RAF-MEK-ERK signalling pathway in ovarian carcinomas. In addition, our observations have an important therapeutic implication in ovarian cancer patients with KRAS or BRAF mutations. Ovarian carcinomas with KRAS or BRAF mutation are clinically low-grade carcinomas of serous or other histological subtypes that are often refractory to conventional cytotoxic chemotherapy (Bristow et al, 2002a, b; Winter et al, 2007). Therefore, detection of KRAS and BRAF mutations in ovarian cancers may identify patients who will benefit from CI-1040 therapy.

\section{ACKNOWLEDGEMENTS}

This study is supported by grants from the Ministry of Education, Culture, Sports, Science and Technology in Japan, and the Japan Society of Gynecologic Oncology.

Supplementary Information accompanies the paper on British Journal of Cancer website (http://www.nature.com/bjc)

\section{REFERENCES}

Allen LF, Sebolt-Leopold J, Meyer MB (2003) CI-1040 (PD184352), a targeted signal transduction inhibitor of MEK (MAPKK). Semin Oncol 30: $105-116$

Arteaga CL, Baselga J (2004) Tyrosine kinase inhibitors: why does the current process of clinical development not apply to them? Cancer Cell 5: $525-531$

Bristow RE, Gossett DR, Shook DR, Zahurak ML, Tomacruz RS, Armstrong DK, Montz FJ (2002a) Micropapillary serous ovarian carcinoma: surgical management and clinical outcome. Gynecol Oncol 86: $163-170$

Bristow RE, Gossett DR, Shook DR, Zahurak ML, Tomacruz RS, Armstrong DK, Montz FJ (2002b) Recurrent micropapillary serous ovarian carcinoma. Cancer 95: $791-800$

Brose MS, Volpe P, Feldman M, Kumar M, Rishi I, Gerrero R, Einhorn E, Herlyn M, Minna J, Nicholson A, Roth JA, Albelda SM, Davies H, Cox C, Brignell G, Stephens P, Futreal PA, Wooster R, Stratton MR, Weber BL (2002) BRAF and RAS mutations in human lung cancer and melanoma. Cancer Res 62: 6997-7000

Davies H, Bignell GR, Cox C, Stephens P, Edkins S, Clegg S, Teague J, Woffendin H, Garnett MJ, Bottomley W, Davis N, Dicks E, Ewing R, Floyd Y, Gray K, Hall S, Hawes R, Hughes J, Kosmidou V, Menzies A, Mould C, Parker A, Stevens C, Watt S, Hooper S, Wilson R, Jayatilake H, Gusterson BA, Cooper C, Shipley J, Hargrave D, Pritchard-Jones K, Maitland N, Chenevix-Trench G, Riggins GJ, Bigner DD, Palmieri G, Cossu A, Flanagan A, Nicholson A, Ho JW, Leung SY, Yuen ST, Weber BL, Seigler HF, Darrow TL, Paterson H, Marais R, Marshall CJ, Wooster R, Stratton MR, Futreal PA (2002) Mutations of the BRAF gene in human cancer. Nature 417: 949-954

Gorden A, Osman I, Gai W, He D, Huang W, Davidson A, Houghton AN, Busam K, Polsky D (2003) Analysis of BRAF and N-RAS mutations in metastatic melanoma tissues. Cancer Res 63: 3955-3957

Hsu CY, Bristow R, Cha MS, Wang BG, Ho CL, Kurman RJ, Wang TL, Shih Ie M (2004) Characterization of active mitogen-activated protein kinase in ovarian serous carcinomas. Clin Cancer Res 10: 6432-6436

Kolasa IK, Rembiszewska A, Janiec-Jankowska A, Dansonka-Mieszkowska A, Lewandowska AM, Konopka B, Kupryjanczyk J (2006) PTEN mutation, expression and $\mathrm{LOH}$ at its locus in ovarian carcinomas. Relation to TP53, K-RAS and BRCA1 mutations. Gynecol Oncol 103: $692-697$

Lee JH, Lee ES, Kim YS (2007) Clinicopathologic significance of BRAF V600E mutation in papillary carcinomas of the thyroid: a meta-analysis. Cancer 110: $38-46$

Lievre A, Bachet JB, Le Corre D, Boige V, Landi B, Emile JF, Cote JF, Tomasic G, Penna C, Ducreux M, Rougier P, Penault-Llorca F, Laurent-Puig P (2006) KRAS mutation status is predictive of response to cetuximab therapy in colorectal cancer. Cancer Res 66: $3992-3995$

Marquez RT, Baggerly KA, Patterson AP, Liu J, Broaddus R, Frumovitz M, Atkinson EN, Smith DI, Hartmann L, Fishman D, Berchuck A, Whitaker R, Gershenson DM, Mills GB, Bast Jr RC, Lu KH (2005) Patterns of gene expression in different histotypes of epithelial ovarian cancer correlate with those in normal fallopian tube, endometrium, and colon. Clin Cancer Res 11: 6116-6126

Massarelli E, Varella-Garcia M, Tang X, Xavier AC, Ozburn NC, Liu DD, Bekele BN, Herbst RS, Wistuba II (2007) KRAS mutation is an important predictor of resistance to therapy with epidermal growth factor receptor tyrosine kinase inhibitors in non-small-cell lung cancer. Clin Cancer Res 13: $2890-2896$

Mizumoto Y, Kyo S, Mori N, Sakaguchi J, Ohno S, Maida Y, Hashimoto M, Takakura M, Inoue M (2007) Activation of ERK1/2 occurs independently of KRAS or BRAF status in endometrial cancer and is associated with favorable prognosis. Cancer Sci 98: 652-658

Nakayama K, Miyazaki K, Kanzaki A, Fukumoto M, Takebayashi Y (2001) Expression and cisplatin sensitivity of copper-transporting P-type adenosine triphosphatase (ATP7B) in human solid carcinoma cell lines. Oncol Rep 8: $1285-1287$

Nakayama K, Nakayama N, Kurman RJ, Cope L, Pohl G, Samuels Y, Velculescu VE, Wang TL, Shih Ie M (2006) Sequence mutations and amplification of PIK3CA and AKT2 genes in purified ovarian serous neoplasms. Cancer Biol Ther 5: 779-785

Oda K, Stokoe D, Taketani Y, McCormick F (2005) High frequency of coexistent mutations of PIK3CA and PTEN genes in endometrial carcinoma. Cancer Res 65: 10669-10673

Oliveira C, Velho S, Moutinho C, Ferreira A, Preto A, Domingo E, Capelinha AF, Duval A, Hamelin R, Machado JC, Schwartz Jr S, Carneiro F, Seruca R (2007) KRAS and BRAF oncogenic mutations in MSS colorectal carcinoma progression. Oncogene 26: 158-163

Olson JM, Hallahan AR (2004) p38 MAP kinase: a convergence point in cancer therapy. Trends Mol Med 10: 125-129

Peyssonnaux C, Eychene A (2001) The Raf/MEK/ERK pathway: new concepts of activation. Biol Cell 93: 53-62

Pohl G, Ho CL, Kurman RJ, Bristow R, Wang TL, Shih Ie M (2005) Inactivation of the mitogen-activated protein kinase pathway as a potential target-based therapy in ovarian serous tumors with KRAS or BRAF mutations. Cancer Res 65: 1994-2000

Preto A, Figueiredo J, Velho S, Ribeiro AS, Soares P, Oliveira C, Seruca R (2008) BRAF provides proliferation and survival signals in MSI colorectal carcinoma cells displaying BRAF(V600E) but not KRAS mutations. J Pathol 214: $320-327$ 
Rinehart J, Adjei AA, Lorusso PM, Waterhouse D, Hecht JR, Natale RB, Hamid O, Varterasian M, Asbury P, Kaldjian EP, Gulyas S, Mitchell DY, Herrera R, Sebolt-Leopold JS, Meyer MB (2004) Multicenter phase II study of the oral MEK inhibitor, CI-1040, in patients with advanced nonsmall-cell lung, breast, colon, and pancreatic cancer. J Clin Oncol 22: $4456-4462$

Schaeffer HJ, Weber MJ (1999) Mitogen-activated protein kinases: specific messages from ubiquitous messengers. Mol Cell Biol 19: $2435-2444$

Schwartz DR, Kardia SL, Shedden KA, Kuick R, Michailidis G, Taylor JM, Misek DE, Wu R, Zhai Y, Darrah DM, Reed H, Ellenson LH, Giordano TJ, Fearon ER, Hanash SM, Cho KR (2002) Gene expression in ovarian cancer reflects both morphology and biological behavior, distinguishing clear cell from other poor-prognosis ovarian carcinomas. Cancer Res 62: $4722-4729$

Sebolt-Leopold JS (2004) MEK inhibitors: a therapeutic approach to targeting the Ras-MAP kinase pathway in tumors. Curr Pharm Des 10: $1907-1914$

Sebolt-Leopold JS, Dudley DT, Herrera R, Van Becelaere K, Wiland A, Gowan RC, Tecle H, Barrett SD, Bridges A, Przybranowski S, Leopold WR, Saltiel AR (1999) Blockade of the MAP kinase pathway suppresses growth of colon tumors in vivo. Nat Med 5: 810-816

Sebolt-Leopold JS, Van Becelaere K, Hook K, Herrera R (2003) Biomarker assays for phosphorylated MAP kinase. Their utility for measurement of MEK inhibition. Methods Mol Med 85: $31-38$

Shih Ie M, Kurman RJ (2004) Ovarian tumorigenesis: a proposed model based on morphological and molecular genetic analysis. Am J Pathol 164: $1511-1518$

Shih Ie M, Kurman RJ (2005) Molecular pathogenesis of ovarian borderline tumors: new insights and old challenges. Clin Cancer Res 11: $7273-7279$

Sieben NL, Macropoulos P, Roemen GM, Kolkman-Uljee SM, Jan Fleuren G, Houmadi R, Diss T, Warren B, Al Adnani M, De Goeij AP, Krausz T,
Flanagan AM (2004) In ovarian neoplasms, BRAF, but not KRAS, mutations are restricted to low-grade serous tumours. J Pathol 202: 336 - 340

Singer G, Kurman RJ, Chang HW, Cho SK, Shih Ie M (2002) Diverse tumorigenic pathways in ovarian serous carcinoma. Am J Pathol 160: $1223-1228$

Singer G, Oldt III R, Cohen Y, Wang BG, Sidransky D, Kurman RJ, Shih Ie M (2003) Mutations in BRAF and KRAS characterize the development of low-grade ovarian serous carcinoma. J Natl Cancer Inst 95: 484-486

Solit DB, Garraway LA, Pratilas CA, Sawai A, Getz G, Basso A, Ye Q, Lobo JM, She Y, Osman I, Golub TR, Sebolt-Leopold J, Sellers WR, Rosen N (2006) BRAF mutation predicts sensitivity to MEK inhibition. Nature 439: $358-362$

Tashiro H, Blazes MS, Wu R, Cho KR, Bose S, Wang SI, Li J, Parsons R, Ellenson LH (1997) Mutations in PTEN are frequent in endometrial carcinoma but rare in other common gynecological malignancies. Cancer Res 57: $3935-3940$

Wan PT, Garnett MJ, Roe SM, Lee S, Niculescu-Duvaz D, Good VM, Jones CM, Marshall CJ, Springer CJ, Barford D, Marais R (2004) Mechanism of activation of the RAF-ERK signaling pathway by oncogenic mutations of B-RAF. Cell 116: $855-867$

Wingo PA, Tong T, Bolden S (1995) Cancer statistics, 1995. CA Cancer J Clin 45: $8-30$

Winter III WE, Maxwell GL, Tian C, Carlson JW, Ozols RF, Rose PG Markman M, Armstrong DK, Muggia F, McGuire WP (2007) Prognostic factors for stage III epithelial ovarian cancer: a Gynecologic Oncology Group Study. J Clin Oncol 25: $3621-3627$

Workman P (1998) United Kingdom Co-ordinating Committee on Cancer Research (UKCCCR) Guidelines for the Welfare of Animals in Experimental Neoplasia (Second Edition). Br J Cancer 77: 1-10

Yamamoto K, Kikuchi Y, Kudoh K, Nagata I (2000) Modulation of cisplatin sensitivity by taxol in cisplatin-sensitive and -resistant human ovarian carcinoma cell lines. J Cancer Res Clin Oncol 126: 168-172 